\title{
Students' Affective Belief as the Component in Mathematical Disposition
}

\author{
Porferio M. Almerino, Jr. ${ }^{1}$, Jonathan Olores Etcuban ${ }^{1 *}$, Cionelyn G. De Jose ${ }^{2}$, \\ Jana Gloria F. Almerino ${ }^{1}$
}

\author{
${ }^{1}$ Cebu Technological University, PHILLIPPINES \\ 2 Southern Leyte State University, PHILLIPPINES \\ *CORRESPONDENCE: $\$ joetcuban@gmail.com
}

\begin{abstract}
This research evaluated the extent of students' affective beliefs towards mathematics at Southern Leyte State University (SLSU), Sogod, Southern Leyte, Philippines as the basis for a Mathematical Disposition Intervention Plan. The study employed descriptive research as the investigation centers on the extent of the students' affective beliefs towards mathematics using a random sampling and Slovin's formula in the determination of the respondents. The quantitative data were treated using frequency, simple percentage, weighted mean, and the Mann-Whitney U-test. The investigation uncovered that there was no significant mean difference in the affective beliefs between male and female respondents. It is concluded that affective beliefs had indeed influenced the mathematical disposition of the students. Albeit, the investigation was answered. Still, it is recommended that future studies shall be made to scrutinize other confounding variables that may cause the students to dislike the subject matter.
\end{abstract}

Keywords: mathematical disposition, affective belief

\section{INTRODUCTION}

Mathematics, as an academic discipline, is vital in every person's usual routine and each day living aside from its influence in the study of other subjects, which all concerned teachers/instructors must practically educate during the delivery of the intended lessons to their students. Whether at a global or local scene, this claim is entirely contrary to the insights of several students who either dislike or hate mathematics as an academic discipline.

There had been claims that the learners from the developed nations have pessimistic perceptions and beliefs on mathematics (Gadanidis, 2012). Such discipline was viewed to be a highly complicated subject matter that only those brilliant and strong-willed learners can well tackle the same. There was this empirical investigation, which disclosed that mathematics is an abstract, sophisticated and exclusive discipline (Mutodi \& Ngirande, 2014).

What these students have consistently shrugged off is contrary to the reality how mathematics is crucial across almost all academic disciplines such as in an accounting or commerce course specifically in some of its business-related lessons like the debit, credit, rate of interest or annuities which had considered usage of the fundamental arithmetic; its several applications in science-based topics such as physics for engineering courses where the necessary computations like velocity, acceleration, impulse, and momentum are calculated; a few of its practical functions in a short-term course like the culinary arts where determination of the

Article History: Received 21 March $2019 \bullet$ Revised 18 April $2019 \bullet$ Accepted 21 April 2019

(C) 2019 by the authors; licensee Modestum Ltd., UK. Open Access terms of the Creative Commons Attribution 4.0 International License (http://creativecommons.org/licenses/by/4.0/) apply. The license permits unrestricted use, distribution, and reproduction in any medium, on the condition that users give exact credit to the original author(s) and the source, provide a link to the Creative Commons license, and indicate if they made any changes. 
prescribed cooking temperature and the required mixture-volume during food preparations are so essential to meet the necessitated or standard taste.

What could have possibly caused this students' disregard towards such discipline is still an exciting quest for every concerned researcher along this field to search for more definitive answers continually. On this note, there was this study which traced how people viewed and believed mathematics as a cold and abstract discipline to originate from their past exposures and experiences. Despite the beauty of its existence in several relevant lessons and real-life events, the common tenet still narrates that several of the learners hate mathematics for its being a complicated subject matter which is difficult to engage scholastically.

In a particular study, it was pointed out that the low participation of the learners in mathematics was caused by their hardship, deficiency in their self-efficacy, and their hate towards it (Brown et al., 2008). The researchers have observed this condition among her students who expressly shared how they dislike/hate the discipline. The latter affective-related biases could be pointed out to various factors, which were connected to the learning domains and learning environment, curriculum contents, delivery of instructions and other confounding variables, which are yet to be scrutinized.

Furthermore, separate research pointed out that the difficulty in comprehending the math lessons as well as a fair delivery of instruction has caused the learners to dislike the subject matter. Also, the need to have a longer time to grasp the necessitated concepts and principles in mathematics has also been an issue among the concerned learners to forget what is just learned quickly. Even though that the discussions are so made well to transfer intended mathematical concepts and principles, the difficulty of understanding on a specific topic among the college students was still noticed, too, by the researchers in their classes. Sadly, these prevailing affective beliefs among the students in all curriculum level that mathematics is a very intricate subject to deal with has received increased attention and more importantly often challenged nearly all knowledge facilitators as to the manner on how it must be addressed or intervened, respectively.

With the preceding, the researchers see the vitality to contribute in assessing, at least in her level, on the "what," "why," "where," and "how" questions toward the students' beliefs which viewed how complex mathematics is as a subject matter to engage on. It is further the direction of this scientific investigation to hopefully arrive at a nearer inference and eventual resolution of the variable under reviews in the real environment where she currently works for an eventual introduction of a mathematical disposition intervening plan to all concerned school administrators, faculty members, and stakeholders.

\section{RELATED LITERATURE}

Few studies revealed that mathematics education had concentrated more on the cognitive domain rather than on the affective domain, which the researchers deemed it imperative to take a more in-depth look on the latter specifically towards belief. Somehow, central to this original empirical intent is scrutiny on whether the affective beliefs of the tertiary level students from the identified locale have influenced their mathematical disposition or not.

Somehow, this particular study is anchored on multiple authorities since defining the word belief still did not arrive at a consensus as shown on some reviews on those related literature. Hence, the exploration on what our beliefs are based on the scientific investigation made by Goldin et al. (2011) while the discussion on the belief system is hinged on the research made.

As a prelude to the main discussions on beliefs, it is essential to refer first the reviews on the affective domain as it has long been recognized as a critical aspect of mathematics and has generally been investigated across four areas: beliefs, values, attitudes, and emotions (Lomas et al., 2008). Hence, understanding the concept of efficiency is vital in the study of the students' affective beliefs towards academic discipline. 


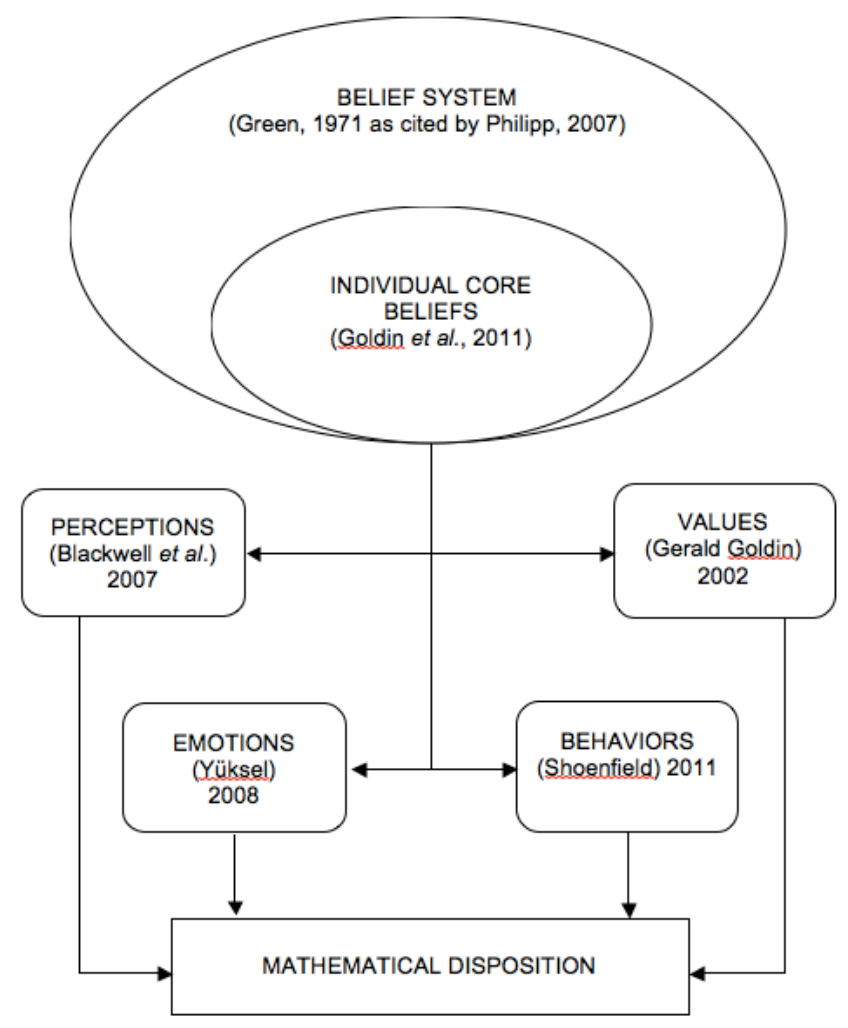

Figure 1. Conceptual Framework of the Study

On "Beliefs." In other relevant and related scientific investigations, the word beliefs had been usually and freely associated with the term value, outlook, viewpoint, and sometimes on the way of life. Conversely, a particular scientific study pointed out that these various equivalencies of the term on the word belief must be assessed well because of their overlapping nature. Aside from this, these equivalent terms are not directly observable, therefore, producing a unique definition of the same is not that so easy indeed (Leder \& Forgasz, 2002). However, Goldin et al. (2011) had laid down a unifying definition of what belief is. The latter authors asserted the claim that the word belief should contain a multiply-encoded configuration which involved the minds and emotions.

Despite the debate regarding the nature of beliefs, three aspects regarding the psychological structure of beliefs are widely accepted. First, beliefs are theorized to be held not in isolation but rather to exist as part of the belief system organized around a key idea or object (Philipp, 2007). Most researchers agree that beliefs are best categorized by the specific idea or object to which they belong - like in the case where the students of the researcher who believe that mathematics is a complicated subject matter to deal or engage with. Hence, the continual labeling that had been used across the domain had discussed the involvement of the viewpoints on mathematics, disposition about self, and the valuing about the social context of mathematical learning.

Second, the stability of an individual belief can be thought of regarding its centrality within the system. Peripheral beliefs are considered less stable and possibly most easily changed. Third, the relationships between beliefs within a system may be held in a quasi-logical structure in which primary beliefs serve as foundational to derivative beliefs (Goldin et al., 2009). Thus, mathematical beliefs held by adult learners are likely to be consistent, which provides a reinforcing system of support towards the positive viewpoints of how mathematics is either an exciting or challenging subject matter.

Acceptably, anyone's beliefs particularly in mathematics may be shared or not at all to others. As they put it, the believers hold such psychological dispositions towards such discipline that come most often of in an affective nature. Few kinds of research there were which inferred that in teaching and learning the mathematical discipline, the beliefs of a learner play a salient part of it. The performance and achievements among these learners are traced to their individual beliefs and attitude as well on such academic discipline (Furinghetti \& Pehkonen, 2002). Accordingly, a particular investigation divulged that the unacceptable 
engagement of the learners, cognitively and affectively, had been negatively influenced from their problematic mathematical histories, which have developed that unwelcomed belief (Muis, 2008).

As a consequence, stopping and leaving from school is an option that these learners could think upon. In return, this will cause the young learners to have a lasting perception of how difficult or complex mathematics is as an academic discipline towards adulthood. When confronted with mathematical tasks in the future, the same adult learners in many cases may experience anxiety over it. Thus, could the beliefs of other individuals influence another person's belief is an interesting question that the belief system shall address.

It was somehow established that a belief system of a person is highly organized that can, however, be culturally embraced. Correspondingly, scientific scrutiny still on the belief system endorses the assertion that the same is not exactly similar to that of the normative beliefs. On the other hand, Goldin (2002) points out that although the belief system can be defined in general perspective, the individual's beliefs on this matter are almost similarly intertwined principally when the person's belief system towards mathematics could be viewed as his/her perception of what the discipline is all about on a personal note.

The latter can be further explained by a concept which articulates that some beliefs are from the very core of the believers while some are being acquired or derived from other person's belief system. For example, when a learner thinks that the subject matter is essential in his/her life, then such condition could be referred to as his/her primary beliefs. However, when this learner proceeded to carry out patiently the drills and exercises in mathematics or try to connect the practical uses or applications of the same to every life's routine, then these two perspectives explain well the beliefs, which were derivative in its form.

Secondly, Green (1971) posited that between the central and peripheral beliefs, the latter ones could be possibly revised while the former are more salient and held robustly most. For example, a neophyte in-service teacher in the school carries more peripheral beliefs and the same are random and flexible than those seasoned facilitators. Nonetheless, the latter category of teachers holds that beliefs which are more central and wellestablished. These teachers may have such central beliefs, which pressed their longevity of service to ascertain what teaching approach is efficient or affective. Given such a scenario here, indeed there were probable scenarios or situations where one's dispositions could cause hindrance in the aspect of development. With this, any standards on curriculum change, learning resources, class supervisions and the like cannot influence the teachers' notion of what good mathematics teaching.

Thirdly, use of the word "cluster" had been considered by the same authorities where they explained that beliefs come in collective unison and are reliant from one to the others. On a personal note, this can be explained that a learner's viewpoint that mathematics is an abstract matter could be of distinct disposition with the other learners from the same class section. Somehow, those beliefs that are common within the section may also have similar viewpoints from the other section that perceived mathematics in another perspective as a complex discipline. However, a weak relationship could exist in the clusters mainly when dealing with this matter where contradictions in students' and teachers' beliefs happened.

With this, the interface between Individual and social beliefs necessitates further reviews as it will assist in understanding their respective impact from one to another. Kluegel and Smith (2017) suggest that beliefs and belief systems provide the cognitive and social conditions in which negative emotional and attitudinal aspects of affect thrive. With this matter, the individual beliefs that influence personal feelings, manner, belief structures, principles, ethics, and morals shall also be exposed to the social beliefs system (Sekerka \& Bagozzi, 2007).

The personal beliefs could also be attributed to the other human beings especially when an individual is the focus of another's severe emotions (Avramidis \& Norwich, 2002; Diener et al., 1997). With this declaration, it was indeed acknowledged that people had the aptness to display somehow what they genuinely feel or personally believe in consideration of the general norms (Goldin, 2002). In fact, the belief systems of other people could influence one's viewpoints which could frequently offer reliable feedback such as (1) emotions being shared, (2) those acceptable attitudes, (3) belief systems within the subgroups in such concerned community, and (4) the circle of friends, elderly adults with the family and the institution which talks on values, ethics and morals (Goldin, 2002). All of these articulations can somehow impact the individual beliefs unless the person submits to such influence.

Beliefs to Perceptions. Previous and latest researches continually demonstrate that beliefs influence perception. Blackwell et al. (2007) found out that learners who believe that mathematical ability is innate and fixed tend to conclude that mathematics proficiency is a measure of intellect. Sadly, this particular empirical finding is nonetheless consistent with the actual observations on the researcher's tertiary-level students who 
are taking up a business and management-related courses. These students perceived that mathematics is only for those bright students. They further shared their viewpoints on how unfair the discipline was for those who are not so good in numbers. Indeed, their dispositions towards mathematics are displaced by such perceptive belief.

Beliefs to Values. People usually have the impressions that beliefs are similar to the values of an individual (De Dreu \& Van Kleef, 2004; Haslam et al., 2004). Thus, they have both the tendency to be closely interchanged in which the disparity can be so slim such that the latter are often termed in everyday language as beliefs. For example, one might say that he/she values learning, or that he/she believes learning is valuable. Assessing this articulation, the comparison should be psychological, as values shall come in the perspective of what held to be desirable instead of what must be logically correct as a personal choice of the person. However, when a person accommodates these truths as a form of values, which are reaffirmed by social agreement, religious creed or authority, these truths, in turn, become a belief and a value. As cited by Etcuban et al. (2019) that teachers should update their strategies and methodologies in teaching Mathematics for the growth and welfare of the students. Thus, as a knowledge facilitator of these college students from the identified university, it is imperative that the period or grade-level where the valuing of mathematics as an essential discipline, which is practically useful on their daily living, must be built in their belief system. In such a manner, when these beliefs on how valuable mathematics is in their life will indeed reshape their thought on it somehow.

Beliefs to Emotions. It should be considered that mathematical anxieties among students are primarily factored out by their beliefs that the subject matter is complicated where such emotional uncertainties and apprehensions both are felt. Specific research along this topic, the study revealed inconclusive results of how the gender of a person is being scrutinized for its relationship with anxiety towards mathematics. Nevertheless, such scientific investigations have revealed that female participants have a higher level of anxiety than those of the male counterpart (Yüksel-Sahin, 2008).

Beliefs to Behaviors. While adults with poor numeracy were engaged in mathematics in school, they are learning about what mathematics is, how it is learned, and what their relationship to it is (Shoenfield, 2011). The scenario presented here is imagery of a behavior that is influenced by the positive beliefs of the person towards mathematics. Contrary to the latter, this learning will appear to contribute to the formation of beliefs that constrain the development of conceptual understanding and contribute to the negative affective responses to mathematics.

It should be well-noted that beliefs have a relationship with behaviors contrary to those recommended by researcher-based reforms that emphasize the conceptual understanding rather than procedural fluency. Acceptably, how one believes in a particular event or case determines also how he/she may behave. On the aspect of how few of the researcher's students take action in trying to resolve issues of dislike in math about a specific belief, they indeed would behave contrary to the norms. Thus, they are also less likely to collaborate and less likely to monitor their progress and make changes where necessary (Muis \& Franco, 2009).

These literatures are essential in the formulation of the study, which are deemed necessary in the conduct of the study.

\section{OBJECTIVES OF THE STUDY}

This study evaluated the extent of students' affective beliefs towards Mathematics at Southern Leyte State University (SLSU), Southern Leyte, Philippines. The findings served as the basis for the Mathematical Disposition Intervention Plan. It answered the: 1) Profile of the respondents; 2) Extent of students' affective beliefs towards mathematics; and 3) Significant mean difference on the affective beliefs between the male respondents and their counterpart.

\section{METHODOLOGY}

This research subscribed to a descriptive research method as the investigation centers on the extent of the students' affective beliefs towards mathematics. It was conducted at SLSU, which offered various academic programs from baccalaureate to graduate studies. The researchers considered the 155 students from the College of Business Administration, who are enrolled during the school year 2018 - 2019 and were selected through random sampling technique. 
This research has adopted the manner on how the Mathematics Self-Efficacy and Anxiety Questionnaire (MSEAQ) was crafted by Dr. Diana K. May in her dissertation last August 2009 for the graduate studies in Doctor of Philosophy at the University of Georgia, Athens. More or less, $50 \%$ of the statements were rephrased to suit the desired statements, which will indeed evaluate the extent of the students' affective beliefs towards mathematics. For this matter, the tests for reliability and validity had been considered as well as the conduct of a necessitated number of pilot testing on such amended survey questionnaire before its last administration to the respondents. Such amended survey questionnaire comes in three folds, namely: Part-1 shall do profile inventory of the respondents in terms of age, gender, and the grade-level where the dislike or like in mathematics started; Part-2 shall assess the extent of the students' affective beliefs towards the identified academic discipline with the 30-item questions which shall be rated using a three-point Likert scale.

After all, communications were in place and approved, the next phase of work was the actual administration of the survey questionnaire to the respondents at a time most convenient to both parties concerned. The retrieval of the questionnaire was contingent upon the completion of the same or in an agreed duration or period where the materials were ready for collection. From this activity, the data, which have been gathered from the survey, were collated, statistically treated using the appropriate tools. Furthermore, once the scientific results were all ready for disclosures, the presentation, analysis, and interpretation of the data after that followed.

The gathered data from the survey were statistically inferred using frequency, simple percentage, weighted mean, and Mann-Whitney U-test.

\section{RESULTS AND DISCUSSIONS}

The profile of the respondents, as to age, gender, and the grade level when they dislike or like on math started, was an essential sub-variable to consider as it can somehow influence the extent of the students' affective beliefs towards the discipline-based from the previous and incumbent studies. Hence, it is imperative to scrutinize each element therein singularly.

\section{Age and Gender of the Respondents}

Conversely, a person's belief could be affected by his/her age and gender orientation in the personal views of the researcher given the many encounters and experiences with the other individuals - including her students - on various issues and matters. As to the recent study, the age and gender, as sub-variables under review, are equally salient matters to dig into particularly on how one's beliefs were either strengthened or accordingly reshaped by them as shown in Table 1 .

Table 1. Respondents' Age and Gender

\begin{tabular}{|c|c|c|c|c|c|c|}
\hline \multirow{2}{*}{$\begin{array}{c}\text { Age Range } \\
\text { (in years) }\end{array}$} & \multicolumn{2}{|c|}{ Male } & \multicolumn{2}{|c|}{ Female } & \multicolumn{2}{|c|}{ Total } \\
\hline & $\mathbf{f}$ & $\%$ & f & $\%$ & f & $\%$ \\
\hline $25 \&$ above & 5 & 3.2 & 14 & 9.0 & 19 & 12.3 \\
\hline $24-25$ & 5 & 3.2 & 5 & 3.2 & 10 & 6.5 \\
\hline $22-23$ & 1 & 0.6 & 10 & 6.5 & 11 & 7.0 \\
\hline $20-21$ & 9 & 5.8 & 51 & 32.9 & 60 & 38.7 \\
\hline $18-19$ & 3 & 1.9 & 46 & 29.7 & 49 & 31.6 \\
\hline $16-17$ & 0 & 0.0 & 6 & 3.9 & 6 & 3.9 \\
\hline Total & 23 & 14.7 & 132 & 85.2 & 155 & 100.0 \\
\hline
\end{tabular}

In a general review of the table, it was apparent that most of the respondents were female students aged 20 to 21 years old. It appeared that these students are already at a level of biological maturity, which somehow can now take a decisive stand as to their belief system. In return, such maturity may guide them to contemplate well on whether such beliefs, whether positive or negative, towards mathematics, would warrant introspection. For many adults, the sense of failure with mathematics often consolidates as a mathematical self-identity in which they position themselves as a non-math person (Wedege, 2002). Many adults perceive the mathematics they know, not as mathematics but merely a common sense. Consequently, adults will avoid situations where this perceived inadequacy is exposed to others, and thus experience discomfort when compelled to re-engage with mathematics as part of a tertiary training program.

Conversely, a study was conducted and revealed the common-held beliefs on mathematics as a discipline which is most fitting for the men than the women based on the study conducted on such regard are the resulted to the lower level of self-efficacy among the women towards the mentioned subject matter. These women 
perceived that despite their actual capabilities on mathematics, they somehow think and believe that they are not indeed good in such discipline. Such condition is also a mirror in some instances in the identified locale where the female students that the male students are better than them when it comes to mathematics. This belief is not healthy among women as it will increase their dislike on such academic discipline.

In particular, Beilock et al. (2010) found out that those female students, who were under the tutelage of those primary teachers who have anxiety in mathematics, will likely believe too that such discipline is complex and hard to deal with. Consequently, at the culmination of the academic year, these female students who belonged to such type of teachers with a certain level of mathematical anxiety showed a critical and crucial achievement in this subject when compared to the general population. However, the researcher's actual experiences on how female students are likewise doing quite good against their male counterparts asserted this claim that the issue on gender as regards belief of how difficult mathematics is remained a case to be further studied by interested researchers.

\section{Dislike or Like on Mathematics Started}

At what period of a person's engagement on mathematics that he dislikes or likes have started to take its form is likewise a matter of interest in this recent investigation concerning one's beliefs towards this academic discipline. Such a moment when this emotional state took its preference in the respondents' system may have impacted a positive or negative thought, emotion, behavior or attitude on the latter. Thus, looking back at where the dislikes or likes were coming from necessitated a revisit (see Table 2).

Table 2. Dislikes and Likes on Mathematics

\begin{tabular}{|c|c|c|c|c|c|c|}
\hline \multirow{2}{*}{ Period Started } & \multicolumn{2}{|c|}{ Dislikes } & \multicolumn{2}{|c|}{ Likes } & \multicolumn{2}{|c|}{ Total } \\
\hline & f & $\%$ & $\mathbf{f}$ & $\%$ & f & $\%$ \\
\hline Grades 1-6 & 10 & 6.5 & 31 & 20.0 & 41 & 26.5 \\
\hline Grades 7-10 & 38 & 24.5 & 32 & 20.6 & 70 & 45.1 \\
\hline Grades 11-12 & 18 & 11.6 & 6 & 3.9 & 24 & 15.5 \\
\hline In College & 13 & 8.4 & 7 & 4.5 & 20 & 12.9 \\
\hline Total & 79 & 51.0 & 76 & 49 & 155 & 100.00 \\
\hline
\end{tabular}

The table showed that there were more or less equally responses as to the inventory of dislikes and likes towards mathematics with a $79(51.0 \%)$ out of 155 responses for dislikes against the $76(49.0 \%)$ answers on likes. Nevertheless, as one comes closer to scrutinize the data, it appeared that several dislikes as well as on likes on such academic discipline were traced to commence while the students are still at the Grades 7 to 10 .

As to this particular range of grade-level, a particular study investigated the factors, which triggered the $5^{\text {th }}$ to $8^{\text {th }}$-grade high school students to dislike or hate mathematics. It was found out that the most critical factor is the teachers, which affect the attitude of these high school students towards their engagement of mathematics especially the extent of support that they gave to their students. Furthermore, the same study had revealed that another factor is on how these students think about the practical applications of mathematics in their everyday life as well as self-judgment in learning the subject matter (Marchis, 2011).

Nonetheless, there were also traces of likes at the earlier part of the students' academic engagement with the $31(20.0 \%)$ out 155 responses that fell under the period when they were still at Grades 1-6. This implied that the ways how the primary education teachers delivered the subject matters had indeed influenced the affective beliefs of these students in mathematics. Possible outcomes could be that the students would fear, dislikes, feel anxious or on the contrary would appreciate, interested, motivated to deal with mathematics.

Vividly here, there was this pinpointing of how the belief in mathematics as a problematic subject provided the possibility that the concerned students will indeed dislike the academic discipline. However, the concerned gaps in the achievements in mathematics in the secondary and tertiary levels can be traced from their avoidance of such academic discipline and learning opportunities where the elective courses were taken by most of these students who have high-level anxiety in mathematics than those low-anxiety individuals (Scarpello, 2005).

\section{Extent of Students' Affective Beliefs towards Mathematics}

It is essential to measure the extent of students' affective beliefs towards mathematics to usher the readers or interested researchers to arrive at an appropriate proposal optimally or intervening plan to address the current issues on the general beliefs which suggest that such academic discipline is hard and complex subject matter to deal with. The probable influence of beliefs on the perceptions, values, emotions, and behaviors could 
affect the students' mathematical disposition. Thus, it is warranted that reviews on such regard should be made to factor out its implications.

Beliefs to Perceptions. The belief system of a person may influence his/her perceptions towards a particular condition according to the previous and some recent researches. In fact, on the actual scenarios when students believed that mathematics is a challenging and complex subject matter to deal with, their perceptions toward such discipline are nonetheless affected based on their sharing. Hence, it was the direction of the researcher to digest the impact of such beliefs to one's perceptions (see Table 3).

Table 3. Respondents' Beliefs as to Perceptions

\begin{tabular}{cllll}
\hline Indicators & Mean & StDev & Interpretation \\
\hline I believe that & & & \\
\hline 1. & only men are good in mathematics. & 1.6 & 0.90 & Won't believe \\
\hline 2. & mathematics is a complex subject. & 2.5 & 0.81 & Believed \\
\hline 3. & only the bright or intelligent people can learn mathematics. & 1.7 & 0.93 & Won't believe \\
\hline $4 . \quad$ mathematical ability is inborn and innate. & 2.2 & 0.92 & Fairly believe \\
\hline $5 . \quad$ mathematics is exciting and interesting. & 2.8 & 0.87 & Believe \\
\hline 6. & mathematics is easy for me. & 2.0 & 0.77 & Fairly believe \\
\hline $7 . \quad$ mathematics is boring. & 1.6 & 0.80 & Won't believe \\
\hline Average & $\mathbf{2 . 1}$ & $\mathbf{0 . 8 6}$ & Fairly believe \\
\hline
\end{tabular}

This table disclosed that, in general, the affective beliefs of a person might not influence his/her perception towards thinking that mathematics is a tedious, complicated, challenging or hard subject matters with the overall result of 2.1 rating for the weighted mean with the corresponding description of "Fairly Believe." Such a result meant that the respondent believed that the statements, in a few instances, are correct although the same is not at all consistent with the others' perceptions and experiences. This further implied that there are people who have specific beliefs how severe the discipline was, nevertheless, the same did not influence their viewpoints that in some cases, mathematics could be an interesting subject matter when they likewise received feedbacks from other persons contrary to what they thought upon.

Multiple cases took place here - one who perceived that mathematics is not for the brilliant people and not gender specific while another contradicting scene of math being exciting and interesting as compared to it being a boring subject matter. A brief review of the profile of the respondents gave us the idea that because of the slim deviation between the dislikes and likes among the respondents, plus with their age range that is still at their developing phase, such beliefs had indeed influenced their varying perceptions towards mathematics which is now the focus of concern.

Previous and latest researches continually demonstrate that beliefs influence perception. Learners who believe that mathematical ability is innate and fixed tend to conclude that mathematics proficiency is a measure of intellect. Sadly, this particular empirical finding is nonetheless consistent with the actual observations on the researchers' tertiary-level students who are taking up a business and management-related courses. These students perceived that mathematics is only for those bright students. They further shared their viewpoints on how unfair the discipline was for those who are not so good in numbers. Indeed, their dispositions towards mathematics are displaced by such perceptive belief.

It could not be denied that these viewpoints of the students were affected by what they believed in and were translated to perceive the things, which ought not to be in such a manner. As can be gleaned on the computed data, the different responses only indicate that the latter claim is indeed valid. This is where the difficulty of a teacher or instructor comes in as to how to address or intervene the affective beliefs of the students towards what and how they perceived mathematics as a necessitated tool in their chosen field of specialization.

Beliefs to Values. For years of experience with the college students who were engaging mathematics, it is a usual concern among the knowledge facilitators on how these learners value the different lessons lesser than the other subject matters due to their shared beliefs that roll out the impracticality of the discipline in the daily routine of human beings. With this circumstance, it is therefore imperative to scrutinize how such beliefs may impact the value system of the students towards mathematics (see Table 4). 
Table 4. Respondents' Beliefs as to Values

\begin{tabular}{rlrl}
\hline Indicators & Mean & StDev & Interpretation \\
\hline I believe that & & & \\
\hline $1 . \quad$ mathematics is one of the subjects I like least. & 1.4 & 0.72 & Won't believe \\
\hline $2 . \quad$ mathematics helps me to understand life in general. & 2.8 & 0.82 & Believe \\
\hline $3 . \quad$ it is essential to be good at math in school. & 2.9 & 0.95 & Believe \\
\hline 4. $\quad$ using mathematics outside of school is not that important. & 1.5 & 0.88 & Won't believe \\
\hline $5 . \quad$ mathematics is not important. & 1.3 & 0.82 & Won't believe \\
\hline $6 . \quad$ mathematics is useless to me. & 1.3 & 0.75 & Won't believe \\
\hline $7 . \quad$ mathematics can be applied in my daily living or routine. & 3.1 & 0.89 & Believe \\
\hline $8 . \quad$ mathematics helps those who make important decisions. & 2.8 & 0.85 & Believe \\
\hline Average & $\mathbf{2 . 1}$ & $\mathbf{0 . 8 4}$ & Fairly believe \\
\hline
\end{tabular}

In this table, although the general rating is 2.1 which is having an equivalent description of "Fairly Believe", somehow, there is not much of an issue, problem or concern if one has to take a critical examination of each statement here, where unanimous beliefs of the students leaned towards how valuable mathematics was to their lives or course based on their overall responses. Gladly, all of their affective beliefs on valuing the discipline are indicative of positive outlooks on this academic discipline.

Just the same, the reckoning point of this condition could be traced from the profile of these respondents where a slight difference there was between the replies on "dislikes" against the "likes" at the right grades or levels when parents are expectedly around to guide them of a value system.

Accordingly, a particular study discussed that people usually have the impressions that beliefs are similar to the values of an individual. Thus, they have both the tendency to be closely interchanged in which the disparity can be so slim such that the latter are often termed in everyday language as beliefs. For example, one might say that "he/she values learning," or that "he/she believes learning is valuable." Assessing this articulation, the comparison should be psychological as values shall come in the perspective of what held to be desirable instead of what must be logically correct as a personal choice of the person. However, when a person accommodates these truths as a form of values, which are reaffirmed by social agreement, religious creed or authority, these truths, in turn, become a belief and a value.

Furthermore, the different values shared among the people in a community including how their ethics and expectations are formed become a part of that cultural representation. Nonetheless, those values acquired and developed by a child at its earlier stage of emotional development comprise that portion of his/her internal representation, which derived the most influencing aspect of his/her drive to define what life is all about. Thus, as a knowledge facilitator of these college students from the identified university, it is imperative that the period or grade-level where the valuing of mathematics as an essential discipline, which is practically useful on their daily living, must be built in their belief system. In such a manner, when these beliefs on how valuable mathematics is in their life will indeed reshape their thought on it somehow.

Beliefs to Emotions. An individual's emotion is a dynamic state of feeling as it can change through times principally when the right stimulus hits it. As to the issue of how the student's beliefs could take part in the reformation of one's manner remained an open call among the knowledge facilitators to address. In this recent study, it is the target of the researcher to see how well the beliefs could influence the emotions of the students who are engaging in mathematics.

Emotion, acceptable, is complex and hard to weigh no matter what circumstance an individual has to dwell in empathically. Nevertheless, for this current study, the focus of scrutiny was on how the useful beliefs of the students impacted more on their feelings towards mathematics (see Table 5). 
Table 5. Respondents' Beliefs as to Emotions

\begin{tabular}{|c|c|c|c|}
\hline Indicators & Mean & StDev & Interpretation \\
\hline \multicolumn{4}{|l|}{ I believe that } \\
\hline 1. I cannot do well on any mathematics test. & 2.4 & 0.71 & Fairly believe \\
\hline 2. I can quickly complete the assignments in mathematics. & 2.2 & 0.69 & Fairly believe \\
\hline 3. I am the kind of person who is good at mathematics. & 2.1 & 0.76 & Fairly believe \\
\hline 4. I cannot understand the contents in math even if explained. & 2.0 & 0.80 & Fairly believe \\
\hline 5. I do not need to know mathematics. & 1.4 & 0.80 & Won't believe \\
\hline 6. I will not be able to use mathematics in my future career. & 1.5 & 0.77 & Won't believe \\
\hline 7. I can become clever in mathematics if I learn all the rules. & 2.7 & 0.93 & Believe \\
\hline 8. I never get tired of doing mathematics. & 2.2 & 0.78 & Fairly believe \\
\hline Average & 2.1 & 0.78 & Fairly believe \\
\hline
\end{tabular}

With an overall rating of 2.1 and corresponding interpretation of "Fairly Believe" is suggestive of the case that the students believed that the survey statements, in few instances, are correct although the other perceptions and experiences are not consistent at all. Such results if further analyzed us directly to note that there were two salient items to consider which are crucial to how the affective beliefs of these students may influence their emotions.

This implied that the particular statement, in a few cases, is true although the perceptions and experiences of the other people are not that consistent to what the respondents believed in. Reflecting on the profile of the respondents where the "dislikes" garnered a higher percentage at the Grades 7 to 10 could somehow explain how these students may have struggled in comprehending the concepts and principles of the subject matter no matter how the teachers discussed them.

By this scenario, it is possible that the same respondents believed and felt that they do not need to know mathematics given the condition above. With its acquirement of 1.4 marking for its weighted mean and corresponding interpretation of "Won't Believe" is indicative of the general views that the statement, in all circumstances, is not true as to what he/she and others deem should be. Presumably, this is an emotional state of the respondents where withdrawal from the incumbent feeling caused by the inability to understand the contents in math even if explained had overshadowed the desire to manage the same. Hence, this is where anxiety may crawl in towards their belief systems, which eventually will negatively consummate their emotions.

Specific research along this topic, the study revealed that the mathematical anxieties among students are primarily factored out by their beliefs that the subject matter is complicated where such emotional uncertainties and apprehensions both are felt. Specific research along this topic, the study revealed inconclusive results of how the gender of a person is being scrutinized for its relationship with anxiety towards mathematics. Nevertheless, such scientific investigations have revealed that female participants have a higher level of anxiety than those of the male counterpart (Yüksel-Sahin, 2008).

Thus, it is not surprising to note that few of these students under the researcher's classes expressed how they felt based on their bad personal experiences and engagement with mathematics-related lessons.

Beliefs to Behaviors. Most of the students who are under the tutelage of the researcher were having a negative behavior when it comes to any mathematical drills and exercises. The students' beliefs shaped such behaviors on how hard mathematics had been in their chosen field of specialization. Thus, the withdrawal to engage in mathematics is often the results. With such a case, it is necessary to assess how the beliefs of a person could usher either to positive or negative behavior (see Table 6).

Table 6. Respondents' Beliefs as to Behaviors

\begin{tabular}{|c|c|c|c|}
\hline Indicators & Mean & StDev & Interpretation \\
\hline \multicolumn{4}{|l|}{ I believe that } \\
\hline my answer is always incorrect during math drills or exercises & 2.2 & 0.71 & Fairly believe \\
\hline asking questions in my mathematics class is of no sense. & 2.0 & 0.96 & Fairly believe \\
\hline even there is a tutor, and I still would not learn mathematics. & 1.7 & 0.84 & Won't believe \\
\hline preparing for a math exam makes the students get tense. & 2.9 & 2.62 & Believe \\
\hline listening to math instructor in class does not stress me. & 2.5 & 0.79 & Believe \\
\hline mathematics does not suit me. & 1.8 & 0.89 & Fairly believe \\
\hline 7. to become good at math is dependent on hard work. & 2.8 & 0.92 & Believe \\
\hline Average & 2.3 & 1.10 & Fairly believe \\
\hline
\end{tabular}


The table showed that the overall rating for this aspect on beliefs to behaviors was 2.3 for its weighted mean with the corresponding description of "Fairly Believe" which suggested that the survey statements, in few cases, are correct although the same is not at all consistent with the others' perceptions and experiences.

While adults with poor numeracy were engaged in mathematics in school, they are learning about what mathematics is, how it is learned, and what their relationship to it is (Shoenfield, 2011). The scenario presented here is imagery of a behavior that is influenced by the positive beliefs of the person towards mathematics. Contrary to the latter, this learning will appear to contribute to the formation of beliefs that constrain the development of conceptual understanding and contribute to the negative affective responses to mathematics.

It should be well-noted that beliefs have a relationship with behaviors contrary to those recommended by researcher-based reforms that emphasize the conceptual understanding rather than procedural fluency. Acceptably, how one believes in a particular event or case determines also how he/she may behave. On the aspect of how few of the researcher's students take action in trying to resolve issues of dislike in math about a specific belief, they indeed would behave contrary to the norms. Thus, they are also less likely to collaborate and less likely to monitor their progress and make changes where necessary (Muis \& Franco, 2009).

Thus, it is just logical that these college students under the care of the researcher in terms of mathematical instruction would display such behaviors in class drills involving mathematics as their beliefs are of particular influence (see Table 7).

Table 7. Summary Table on Respondents' Beliefs

\begin{tabular}{lccc}
\hline Beliefs & Mean & StDev & Interpretation \\
\hline Perceptions & 2.1 & 0.86 & Fairly believe \\
\hline Values & 2.1 & 0.84 & Fairly believe \\
\hline Emotions & 2.1 & 0.78 & Fairly believe \\
\hline Behaviors & 2.3 & 1.10 & Fairly believe \\
\hline Average & $\mathbf{2 . 2}$ & $\mathbf{0 . 9 0}$ & Fairly believe \\
\hline
\end{tabular}

With the summary of the four aspects that were somehow influenced by affective beliefs, the general rating of 2.2 for its average weighted mean with corresponding description of Fairly Believe pointed to the fact that these respondents in one way or the other deemed that such affective beliefs have impacted their perceptions, values, emotions, and behaviors towards the subject matter. Although the same is not at all consistent with the others' viewpoints and experiences, however, there was indeed such influence on these aspects which is a good point here since there were acknowledgment and acceptance of the situation that a remedy is possible to reinforce such perspective. In return, it is expected therefore that these college students in some points of their academic lives may arrive at a reflective thought and eventually accept the saliency of mathematics in their course, daily routine and life in general.

\section{Test of Significant Mean Difference}

Could the male students be more pragmatic than the female students as in dealing things is a question, which should be given attention? This is the reason why the researcher endorsed the test of significant difference in the affective beliefs between the respondent-groups.

In this part of the paper, the responses made by the male and female respondents towards the four established research sub-variables were inferred using the appropriate statistical tool (see Table 8).

Table 8. Test of Significant Mean Difference Between Respondent Groups

\begin{tabular}{lcccccc}
\hline Variables & z-score & $\begin{array}{c}\text { Computed } \\
\text { U-value }\end{array}$ & $\begin{array}{c}\text { Critical } \\
\text { Value }\end{array}$ & P-value & Interpretation & Decision \\
\hline Perception & 0.95831 & 16.5 & 8 & 0.34 & Not Significant & $\mathrm{H}_{0}$ Accepted \\
\hline Values & 0.31506 & 28.5 & 13 & 0.75 & Not Significant & $\mathrm{H}_{0}$ Accepted \\
\hline Emotions & 0.15753 & 30.0 & 13 & 0.87 & Not Significant & $\mathrm{H}_{0}$ Accepted \\
\hline Behaviors & 0.76665 & 18.0 & 8 & 0.44 & Not Significant & $\mathrm{H}_{0}$ Accepted \\
\hline
\end{tabular}

The table showed that both responses made by the male and female respondents arrived at the acceptance of the null hypothesis given the computed U-values that are greater than the critical values at the same time also the corresponding $\mathrm{p}$-values are likewise more significant than the 0.05 level of significance in this twotailed test. The data here are suggestive of the case where both the male and female respondents both agree 
on their perceptions, values, emotions, and behaviors towards mathematics as a discipline to deal and engage in their chosen course.

\section{CONCLUSIONS}

About the previous findings, it is, therefore, safe to generalize that the affective beliefs of these college students have influenced and even impacted their perceptions, values, emotions, and behaviors towards such academic discipline, which formed their mathematical disposition.

\section{RECOMMENDATIONS}

Indeed there were other confounding variables that were not considered in this scientific study, nonetheless, the following matters are recommended for all interested parties, to wit: 1) The implementation of the Mathematical Disposition Intervening Plan among all concerned mentors or interested school personnel to address the incumbent belief system of the college students from the research environment; and 2) Future researchers are enjoined to dig deeper on the confounding variables which somehow could influence the person's viewpoints, dislikes or likes and the manner he or she reacts on the subject matter.

\section{Disclosure statement}

No potential conflict of interest was reported by the authors.

\section{Notes on contributors}

Porferio M. Almerino, Jr. - Cebu Technological University, Phillippines.

Jonathan Olores Etcuban - Cebu Technological University, Phillippines.

Cionelyn G. De Jose - Southern Leyte State University, Phillippines.

Jana Gloria F. Almerino - Cebu Technological University, Phillippines.

\section{REFERENCES}

Avramidis, E., \& Norwich, B. (2002). Teachers' attitudes towards integration/inclusion: A review of the literature. European Journal of Special Needs Education, 17(2), 129-147. Retrieved from https://goo.gl/QksdcW

Beilock, S. L., Gunderson, E. A., Ramirez, G., \& Levine, S. C. (2010). Female teachers' math anxiety affects girls' math achievement. Proceedings of the National Academy of Sciences, 107(5), 1860-1863. Retrieved from https://goo.gl/DbQch1

Blackwell, L. S., Trzesniewski, K. H., \& Dweck, C. S. (2007). Implicit theories of intelligence predict achievement across an adolescent transition: A longitudinal study and an intervention. Child development, 78(1), 246-263. Retrieved from https://goo.gl/w6rqcG

Brown, M., Brown, P., \& Bibby, T. (2008). "I would rather die": Reasons given by 16-year-olds for not continuing their study of mathematics. Research in Mathematics Education, 10(1), 3-18. Retrieved from https://goo.gl/nYcNB8

De Dreu, C. K., \& Van Kleef, G. A. (2004). The influence of power on the information search, impression formation, and demands in negotiation. Journal of Experimental Social Psychology, 40(3), 303-319. Retrieved from https://goo.gl/7jUnzp

Diener, E., Suh, E., \& Oishi, S. (1997). Recent findings on subjective well-being. Indian Journal of Clinical Psychology, 24, 25-41. Retrieved from https://goo.gl/dKCeSr

Etcuban, J. O., Campanilla, B. S., \& Horteza, A. D. (2019). The use of Mathcad in the achievement of Education students in teaching College Algebra in a university. Int Elect J Math Ed., 14(2), 341-351. Retrieved from https://goo.gl/USwnbd

Furinghetti, F., \& Pehkonen, E. (2002). Rethinking characterizations of beliefs. In Beliefs: A hidden variable in mathematics education? (pp. 39-57). Springer, Dordrecht. Retrieved from https://goo.gl/Jv2pM6

Gadanidis, G. (2012). Why can't I be a mathematician? For the Learning of Mathematics, 32(2), 20-26. Retrieved from https://goo.gl/ahWssQ 
Goldin, G. A. (2002). Affect, meta-affect, and mathematical belief structures. In Beliefs: A hidden variable in mathematics education? (pp. 59-72). Springer, Dordrecht. Retrieved from https://goo.gl/s6wzsZ

Goldin, G. A., Epstein, Y. M., Schorr, R. Y., \& Warner, L. B. (2011). Beliefs and engagement structures: Behind the affective dimension of mathematical learning. $Z D M, 43(4), 547$. Retrieved from https://goo.g1/Rv6pza

Goldin, G., Rösken, B., \& Törner, G. (2009). Beliefs-no longer a hidden variable in mathematical teaching and learning processes. In Beliefs and attitudes in mathematics education (pp. 1-18). Brill Sense. Retrieved from https://goo.gl/ZRwCGv

Haslam, N., Bastian, B., \& Bissett, M. (2004). Essentialist beliefs about personality and their implications. Personality and Social Psychology Bulletin, 30(12), 1661-1673. Retrieved from https://goo.g1/27Fh6c

Kluegel, J. R., \& Smith, E. R. (2017). Beliefs about inequality: Americans' views of what is and what ought to be. Routledge. Retrieved from https://goo.gl/7CktUz

Leder, G. C., \& Forgasz, H. J. (2002). Measuring Mathematical Beliefs and Their Impact on the Learning of Mathematics: A New Approach. In Beliefs: A hidden variable in mathematics education? (pp. 95-113). Springer, Dordrecht. Retrieved from https://goo.gl/aTRhtu

Lomas, G., Grootenboer, P., \& Attard, C. (2012). The affective domain and mathematics education. In Research in Mathematics Education in Australasia 2008-2011 (pp. 23-37). SensePublishers, Rotterdam. Retrieved from https://goo.g1/1wJcLR

Marchis, I. (2011). Factors that influence secondary school students' attitude to mathematics. Procedia-Social and Behavioral Sciences, 29, 786-793. Retrieved from https://goo.gl/eaBC5y

Mizala, A., Martínez, F., \& Martínez, S. (2015). Pre-service elementary school teachers' expectations about student performance: How their beliefs are affected by their mathematics anxiety and student's gender. Teaching and Teacher Education, 50, 70-78. Retrieved from https://goo.g1/CCR3sF

Muis, K. R. (2008). Epistemic profiles and self-regulated learning: Examining relations in the context of mathematics problem solving. Contemporary Educational Psychology, 33(2), 177-208. Retrieved from https://goo.gl/t948Hs

Muis, K. R., \& Franco, G. M. (2009). Epistemic beliefs: Setting the standards for self-regulated learning. Contemporary Educational Psychology, 34(4), 306-318. Retrieved from https://goo.gl/AYHbFT

Mutodi, P., \& Ngirande, H. (2014). The Influence of Students' Perceptions on Mathematics Performance. A Case of a Selected High School in South Africa. Mediterranean Journal of Social Sciences, 5(3), 431. Retrieved from https://goo.gl/osVfKD

Philipp, R. A. (2007). Mathematics teachers' beliefs and affect. Second handbook of research on mathematics teaching and learning, 1, 257-315. Retrieved from https://goo.gl/oMNDqo

Sekerka, L. E., \& Bagozzi, R. P. (2007). Moral courage in the workplace: Moving to and from the desire and decision to act. Business Ethics: A European Review, 16(2), 132-149. Retrieved from https://goo.gl/gZG2mm

Scarpello, G. V. (2005). The effect of mathematics anxiety on the course and career choice of high school vocational-technical education students. Retrieved from https://goo.gl/x63zdN

Wedege, T. (2002). Mathematics-that's what I can't do: People's affective and social relationship with mathematics. Literacy and Numeracy Studies, 11(2), 63. Retrieved from https://goo.gl/rVzaSJ 